\title{
Analysis of Existing Open Standard Framework and Ontologies in the Construction Sector for the Development of Inference Engines
}

\author{
B. Di Martino ${ }^{1(凶)}$, C. Mirarchi ${ }^{2}$, S. Ciuffreda ${ }^{2}$, and A. $\operatorname{Pavan}^{2}$ \\ 1 Department of Engineering, Università della Campania "Luigi Vanvitelli", \\ Aversa, Italy \\ beniamino.dimartino@unina.it \\ 2 Department of Architecture, Built Environment and Construction Engineering, \\ Politecnico di Milano, Milan, Italy \\ \{Claudio.mirarchi, alberto.pavan\}@polimi.it, \\ simone.ciuffreda@mail.polimi.it
}

\begin{abstract}
The definition of shared dictionaries able to facilitate communication in the construction sector has been an open issue long since. The advent of ICT highlighted the existing issues imposing new challenges to allow the communication between systems. Nowadays, the digital transformation in the construction sector is led by Building Information Modelling. Several efforts have been spent both in research and industry developing open standards like the industry foundation classes and related ontologies to empower interoperability. However, this paper highlights the obstacles limiting use and exchange of information at the state of the art.
\end{abstract}

\section{Introduction}

The construction sector is a project-based industry characterized by informativeintensive processes that produce one-of-a-kind products that are characterise by high complexity. Project information is composed by several documents among which graphical drawings traditionally represent a fundamental component thanks to their ability to transfer articulated and complex information in technical and usually shared terms between technicians. However, the high variety of elements that can compose a building or an infrastructure, the geographical dislocation of the products and the increasing number of information requires to design a real estate posed several challenges in the communication between the subjects involved in a construction project. The introduction of Building Information Modelling (BIM) that is the use of object oriented software to develop information models able to transfer information in a structure and collaborative process, can limit the fragmentation of this information. The information models developed in BIM processes can be defined as a shared digital representation of physical and functional characteristics of built objects. However, the peculiarities of the construction sector, such as one-of-a-kind-product, long life-cycle of products, fragmented and spatially distributed chain are challenging the effective 
interoperability (i.e. the exchange and use of information between different systems [1]) in BIM as well as the possibility to effectively use the data contained in the information models. Since 1995, the BuildingSmart consortium is working on the Industry Foundation Classes (IFC), i.e. a common data model to represent and describe building processes [2]. However, the effective application and use of IFC in the construction industry processes demonstrated to be all but easy. The IFC schema comprehends only a small part of all the elements that can be included in a real estate and does not provide a standard classification for other elements or for sub-groups or aggregation of the same building components. Moreover, the study proposed in this paper highlighted several discrepancies between the standards that work together with IFC. This, can hamper the development of automated system able to use the data contained in information models dealing for example to automatic quality checking, code checking, computational design, etc. Thus, there is both a lack in the formal representation of objects to allow their correct use in information models and a lack in the correct semantic identification of these objects even when they are identified.

According to the existing limitation, around 2000 researchers start to explore the use of semantic web technologies to enhance the information exchange processes [3]. Following this trend, the Linked Data Working Group (LDWG) [4] developed the ifcOWL ontology based on the IFC standard and an IFC-to-RDF converter [5].

A common problem in the construction domain is the use of building information models to the automatic verification of the design according to standards, regulations, project requirements, etc. Usually, due to interoperability issues, building information models need to be prepared and improved to allow the application of automated verification processes. The preparation activity includes for example the definition of standard names for each building space, the inclusion of specific information in building object, etc. The automatic identification of both the building spaces destination of use and of real estate units (identified as aggregation of building spaces) can drastically reduce the time required to "prepare" the model for the check phase. The same situation can be extended to several cases of building information models use where the information has to be combined with external inputs and interoperability issues rise. A recent case study developed by the Authors highlighted the relation between the above mention ontological limitations and the difficulties in developing automated means to use building information models contents.

The objective of this work is to analyse the existing structure of the open standards related to IFC with the objective of clearly identify existing issues and relate these issues to the case study developed by the Authors. Moreover, starting from this last, this article will argue about the need of extending the existing ontological structures. This study paves the way for future analysis on the open standard structure that nowadays represent the reference point for the construction industry to promote its improvement according to the increasing needs of interoperability and data uses.

The rest of the paper is organized as follow. Section 2 presents the background related to the development of open standards in the construction sector. Section 3 highlights the open issues and the motivations to this study. Section 4 proposes a compared analysis between the main standards that constitute the semantic shared structure nowadays available in the construction sector. Section 5 deals with the 
implication of the analyzed issues to the development of automated processes to use data and information. Finally, Chapter 6 presents the conclusion and discussion of the article.

\section{Background}

IFC is nowadays recognized and defined in the construction sector as a standard common language. The IFC schema provides the building blocks for interoperability through its open and neutral data structure. It represents geometry, relations, processes and material, performance, fabrication, and other properties, using the EXPRESS language.

However, the use of IFC underlined several issues due to the unclear processes of import and export of IFC files. These processes are usually defined as black box embedded in the specific software used to export and/or import the IFC file. Lack of information in sharing building information models through IFC formats is registered in several cases, e.g. when models are exported and imported in the same BIM authoring tool, from architectural models to structural models, from BIM authoring tools to analysis software (e.g. for energy analysis) or from architectural models to facility management tools. Objects, relations, and attributes can be defined in several ways and their standard identification is defined at a specific level (e.g. ifcSpace) without considering sub-levels (e.g. ifcSpace: kitchen) and aggregation (e.g. ifcRealEstateUnit or IfcBuilding). Hence, data exchange usually needs the definition of ad hoc standards defined by organisation or by project with the consequent difficulties in using the information by means of automated processes.

IFC covers only the transport of data and information in the process. Processes, standard terminology and technical requirements are not included in the IFC schema. Indeed, Building Smart includes five basic standards, namely Information Delivery Manual (IDM), International Framework for Dictionaries (IFD), BIM Collaboration Format (BCF), Model View Definition (MVD), and Industry Foundation Classes (IFC) that all together constitute the standard for the interoperability in the construction sector (Table 1).

Table 1. IFC related standards from BuildingSmart [6]

\begin{tabular}{l|l|l}
\hline Description & Name & Related standard \\
\hline Describe processes & $\begin{array}{l}\text { Information Delivery } \\
\text { Manual } \\
\text { IDM }\end{array}$ & $\begin{array}{l}\text { ISO 29481-1 [7] } \\
\text { ISO 29481-2 [8] }\end{array}$ \\
\hline Transport information/data & $\begin{array}{l}\text { Industry Foundation Class } \\
\text { IFC }\end{array}$ & ISO 16739 [9] \\
\hline Change Coordination & $\begin{array}{l}\text { BIM Collaboration Format } \\
\text { BCF }\end{array}$ & buildingSMART BCF \\
\hline Mapping of Terms & $\begin{array}{l}\text { International Framework for } \\
\text { Dictionaries } \\
\text { IFD }\end{array}$ & $\begin{array}{l}\text { ISO 12006-3 [10] } \\
\text { buildingSMART Data } \\
\text { Dictionary }\end{array}$ \\
\hline $\begin{array}{l}\text { Translates processes into } \\
\text { technical requirements }\end{array}$ & $\begin{array}{l}\text { Model View Definitions } \\
\text { MVD }\end{array}$ & $\begin{array}{l}\text { buildingSMART } \\
\text { MVD }\end{array}$ \\
\hline
\end{tabular}


IDM focuses on processes that require the exchange or share of information between project participants and the information required and resulting from the execution of these processes. It is strictly related to MVD that is the identification of the required model views, i.e. the "subset of the IFC schema that is needed to satisfy one or many exchange requirements", needed for a specific use of the model. IFD provides a systematic collection of terms, vocabulary and attributes to establish a standard semantic in the construction sector. Nevertheless, the IFD is limited to the components defined in the IFC schema and suffer the same issue in the formal representation of building components described in the introduction. Figure 1 proposes the synthesis of the relations between the presented standards.

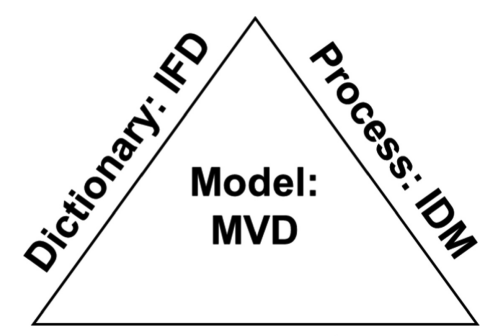

Data: IFC

Fig. 1. Basic open standards from BuildingSmart [6]

From early 2000s researchers start to explore the use of semantic web technologies to enhance the information exchange processes [3]. Nowadays, there is an active research community working on this topic. The BuildingSMART Linked Data Working Group (LDWG) [4] developed the ifcOWL ontology based on the IFC standard. To automate the conversion process between IFC models and RDF models an IFC-to-RDF converter was developed [5]. Nevertheless, the direct use of the IFC into an RDF schema resulted in a complex data structure that can hinder the effective use of the information. Thus, in the literature can be found several studies that focuses on the development of ontologies that can integrate and/or simplify the ifcOWL ontology. The Linked Building Data Community Group at the W3C developed the Building Topology Ontology (BOT) [11]. Moreover, Pauwels and Roxin [12] explored different ways to simplify the ifcOWL ontology. Following the development of the BOT, an IFC to LBD converter was developed [13] while other studies focused on the extension of the BOT [14] and on the relation between existing ontologies and ontologies developed in the construction sector [15].

\section{Motivation}

Even if other studies revealed the need to extend the existing ifcOWL ontology, the proposed extensions are limited to a high level that does not allow the identification through a shared semantics of specific elements such as e.g. types of IfcSpace. 
Moreover, the existing studies focuses on the IFC structure and its translation and/or relation to ontologies but without considering the dictionary used to define these objects. Thus, on the one hand there is the need to clarify the existing open standard configuration to understand the relations and possible issues between the existing standards to promote the development of ontologies that can overcome these problems. On the other hand, a recent study developed by the Authors demonstrated the need to integrate the ontologies nowadays developed to allow automated processes of data use. Hence, these paper proposes two analysis that together can be used to promote and support the development of improvements in the existing structure of open standards in the construction sector.

\section{Comparison Between the Basics Open Standards}

The main goal of the proposed analysis is to clarify the existing overall situation of definitions BuildingSMART uses in writing the different versions of IFC. The framework used in the model definition is defined in ISO 12006 Part 3: Framework for object-oriented Information [10], and it is intended as an EXPRESS-based taxonomy model able to describe relationships between concepts, groupings of elements and their relative properties. ISO 12006 Part 2: Framework for classification [16], instead, aims to define the main classes of objects of Architecture, Engineering and Construction (AEC) field, supported by the definitions of the objects introduced. In giving new definitions of classes, this document also gives an idea of relationship between the elements of construction sector (e.g. a construction result is the output of a construction process, starting from construction resources; a work result is the output of a work process, etc.).

The object-oriented framework proposed by ISO 12006 has been compared to the widely used by IFC and codified in ISO 16739. The analysis tries to match definitions and properties given in the two standards according to the proposed frameworks. The comparison has been held considering both IFC $2 \times 3$ and IFC 4 standards, as they are the most referenced by the industry in interoperability issues. Also, both ISO 12006:2007 and ISO 12006:2015 have been compared, as the updated version introduces several major changes in the definitions and in the framework in which definitions are applied.

Quantitatively, ISO 12006 has less definitions than IFC but, as it has already been sentenced, the first one aims to give narrower information about classes as framework for further application in AEC and civil/infrastructure domains.

Objects defined in ISO 12006 and IFC classes have been matched weighting the relationship between the terms on a five-step scale from $0 \%$ to $100 \%(0 \%, 25 \%, 50 \%$, $75 \%, 100 \%$ ) representing respectively the absence of a match up to a congruent match between the definitions.

\subsection{ISO 12006:2007 to IFC Comparison}

Since ISO 16739 defines the objects while introducing the framework of building objects, ISO 12006-2 terms were put in comparison with IFC definitions to find 
matches or mismatches. ISO 12006-2:2007 introduces a total of 20 terms, as a list, with no relation defined between the objects. The only exception is made in the definition of the terms construction result, construction process, construction resource, work result and work process (see Tables 2 and 3). According to the given definitions, both construction resources and construction results have an input-output relation with construction process, and the same works for work-related definitions.

As it is shown, the two codifications identify two different generalizations of the concept defined as process by IAI in ISO 16739 (a process is defined as objectoccurrence located in time, indicating "when"). The same principles occur in the definition of product (defined as physical or conceptual object that occurs in space, as a specialization of object).

Tables 2 and 3 report an example of the comparison developed between the ISO 12006-2 and the IFC schema highlighting the existing lack of coherence between the two.

Table 2. Example of comparison between ISO 12006-2 and IFC

\begin{tabular}{|c|c|c|c|c|c|c|}
\hline \multirow[t]{2}{*}{ Item } & \multicolumn{2}{|l|}{ UNI 12006-2 } & \multicolumn{2}{|l|}{ IFC } & \multirow[b]{2}{*}{ Notes } & \multirow[b]{2}{*}{$\%$} \\
\hline & Term & Definition & Entity & Definition (from IAI) & & \\
\hline 1 & Object & $\begin{array}{l}\text { Any part of } \\
\text { the } \\
\text { perceivable } \\
\text { world }\end{array}$ & IfcObject & $\begin{array}{l}\text { Generalization of any } \\
\text { semantically treated thing or } \\
\text { process. Objects are things } \\
\text { as they appear, tangible or } \\
\text { non tangible }\end{array}$ & $\begin{array}{l}\text { Supertype in IFC of } \\
\text { Actors, controls, } \\
\text { groups product and } \\
\text { resources }\end{array}$ & 100 \\
\hline 2 & $\begin{array}{l}\text { Construction } \\
\text { object }\end{array}$ & $\begin{array}{l}\text { Object of } \\
\text { importance } \\
\text { to the } \\
\text { construction } \\
\text { industry }\end{array}$ & IfcProduct & $\begin{array}{l}\text { Any object, or any aid to } \\
\text { define, organize and } \\
\text { annotate an object, that } \\
\text { relates to a geometric or } \\
\text { spatial context. Subtypes of } \\
\text { IfcProduct usually hold a } \\
\text { shape representation and a } \\
\text { local placement within the } \\
\text { project structure. In addition } \\
\text { to physical products } \\
\text { (covered by the subtype } \\
\text { IfcElement) and spatial } \\
\text { items (covered by the } \\
\text { subtype } \\
\text { IfcSpatialStructureElement) } \\
\text { the IfcProduct also includes } \\
\text { non-physical items, that } \\
\text { relate to a geometric or } \\
\text { spatial contexts, such as } \\
\text { grid, port, annotation, } \\
\text { structural actions, etc. }\end{array}$ & $\begin{array}{l}\text { Object of } \\
\text { importance may be } \\
\text { represented both by } \\
\text { IfcProduct or } \\
\text { IfcResource }\end{array}$ & 25 \\
\hline
\end{tabular}


Table 3. construction process and work process comparison

\begin{tabular}{|c|c|c|c|c|c|c|}
\hline \multirow[t]{2}{*}{ Item } & \multicolumn{2}{|l|}{ UNI 12006-2 } & \multicolumn{2}{|l|}{ IFC } & \multirow[b]{2}{*}{ Notes } & \multirow[b]{2}{*}{$\%$} \\
\hline & Term & Definition & Entity & Definition (from IAI) & & \\
\hline 11 & $\begin{array}{l}\text { Construction } \\
\text { process }\end{array}$ & $\begin{array}{l}\text { Process which } \\
\text { transforms } \\
\text { construction } \\
\text { resources into } \\
\text { construction } \\
\text { results }\end{array}$ & IfcProcess & $\begin{array}{l}\text { IfcProcess is defined as } \\
\text { one individual activity or } \\
\text { event, that is ordered in } \\
\text { time, that has sequence } \\
\text { relationships with other } \\
\text { processes, which } \\
\text { transforms input in } \\
\text { output, and may connect } \\
\text { to other other processes } \\
\text { through input output } \\
\text { relationships. An } \\
\text { IfcProcess can be an } \\
\text { activity (or task), or an } \\
\text { event. It takes usually } \\
\text { place in building } \\
\text { construction with the } \\
\text { intent of designing, } \\
\text { costing, acquiring, } \\
\text { constructing, or } \\
\text { maintaining products or } \\
\text { other and similar tasks or } \\
\text { procedures }\end{array}$ & $\begin{array}{l}\text { IFC definition is } \\
\text { more inclusive } \\
\text { than the one of } \\
\text { ISO } 12006\end{array}$ & 100 \\
\hline 13 & $\begin{array}{l}\text { Work } \\
\text { process }\end{array}$ & $\begin{array}{l}\text { Predominant } \\
\text { construction } \\
\text { process which } \\
\text { results in a work } \\
\text { result }\end{array}$ & IfcProcess & & $\begin{array}{l}\text { Narrower concept, } \\
\text { possibly subtype } \\
\text { of "construction } \\
\text { process", or } \\
\text { viceversa }\end{array}$ & 50 \\
\hline
\end{tabular}

\subsection{ISO 12006:2015 to IFC Comparison}

One of the innovations brought by the 2015 edition of the ISO 12006 is a new link between the part 2 and the part 3. While in previous editions the scope of bringing out a taxonomy model for the objects was discussed only in one part, in the updated edition ISO working groups have developed new and simpler terms with the goal of clarifying some collisions or misunderstanding in previous definitions. An example of this workflow is visible in Table 4, where the same objects have clearer and coded definition, linked one to each other with different kinds of relations. In this new edition, as a matter of fact, a basic process model is introduced, as the relation between resources, processes and product is clarified; type-of and part-of relationships are defined and introducing properties, still keeping definitions as broad as possible. 
Table 4. ISO 12006-2:2015 to IFC comparison example

\begin{tabular}{|c|c|c|c|c|c|c|c|c|}
\hline \multicolumn{4}{|c|}{ UNI 12006-2 } & \multicolumn{5}{|l|}{ IFC } \\
\hline Item & Code & Term & Definition & $2 \times 3$ & 4 & Entity & Definition (IAI) & $\%$ \\
\hline 8 & 3.1 .8 & Space & $\begin{array}{l}\text { Limited three- } \\
\text { dimensional } \\
\text { extent defined } \\
\text { physically or } \\
\text { notionally }\end{array}$ & & $\mathrm{x}$ & IfcSpatialElement & $\begin{array}{l}\text { A spatial element is the } \\
\text { generalization of all } \\
\text { spatial elements that } \\
\text { might be used to define } \\
\text { a spatial structure or to } \\
\text { define spatial zones }\end{array}$ & 50 \\
\hline 9 & 3.1 .9 & $\begin{array}{l}\text { Activity } \\
\text { space }\end{array}$ & $\begin{array}{l}\text { Space (3.1.8) } \\
\text { defined by the } \\
\text { spatial extension } \\
\text { of an activity }\end{array}$ & & $\mathrm{x}$ & IfcSpatialElement & $\begin{array}{l}\text { A spatial element is the } \\
\text { generalization of all } \\
\text { spatial elements that } \\
\text { might be used to define } \\
\text { a spatial structure or to } \\
\text { define spatial zones }\end{array}$ & 50 \\
\hline 10 & 3.2 .1 & $\begin{array}{l}\text { Construction } \\
\text { agent }\end{array}$ & \begin{tabular}{|l} 
Human \\
construction \\
resource (3.2.5) \\
carrying out a \\
construction \\
process $(3.3 .2)$
\end{tabular} & $\mathrm{x}$ & $\mathrm{x}$ & IfcActor & $\begin{array}{l}\text { The IfcActor defines } \\
\text { all actors or human } \\
\text { agents involved in a } \\
\text { project during its full } \\
\text { life cycle. It facilitates } \\
\text { the use of person and } \\
\text { organization } \\
\text { definitions in the } \\
\text { resource part of the } \\
\text { IFC object model. This } \\
\text { includes name, } \\
\text { address, } \\
\text { telecommunication } \\
\text { addresses, and roles }\end{array}$ & 75 \\
\hline
\end{tabular}

Misleading definitions and overlapping terms are still present in 2015 ISO document, referring to the definition of particular process stages or spaces with or without function. It is stated that all objects can be defined both as objects and also as systems of elements, which are objects themselves.

\section{Automated Use of Information}

In the scientific literature can be found some studies related to the automated recognition of building information models objects. For example, Belsky, Sacks and Brilakis [9] proposed a semantic enrichment engine to recognize building information modelling objects. An improved version of the system was proposed to classify and aggregate prefabricated elements in bridge projects [10]. And a recent experimentation proposes the comparison between the semantic enrichment engine and a machine learning application to recognize room types in information models [11]. Among these studies, the recognition of building spaces is of particular interest due to the related possibility to define automated process to control information models against regulations and/or design requirements. In this direction, the Authors developed an automated 
system based on the ifcOWL that can recognize the characteristics of spaces and identify their uses in the building such as kitchen, bathroom, bedroom, etc. However, the recognition of these elements required the introduction of ad hoc extensions in the ifcOWL ontology because both specific type of ifcSpace and the aggregation of these spaces to identify an apartment are not considered in the ifcOWL. The lack of a shared ontology able to comprehend these concepts leads to the use of ad hoc extensions that creates island of information and knowledge according to the specific application, thus limiting its diffusion and improvement. Hence, starting from the proposed study it is envisioned the need to extend the existing ifcOWL ontology according to the need of the real estate market that sees in the identification of spaces uses and in their aggregation according to the real estate units a crucial area of action (e.g. in selling and renting buildings, in manage maintenance activities, in checking the coherence according to existing regulations, etc.).

\section{Discussion and Conclusions}

Combining the result of the case study presented in Chapter 5 with the ones reported in the existing literature and with the analysis proposed in Chapter 4, it is clear the need to extend the existing ontology and to promote the integration of this ontology with an extended and shared dictionary that is able to identify also for the humans the means of the terms used in the ontological structure. In fact, one of the consequences of narrow definition reported in ISO 12006 is the misunderstanding between users and, most importantly, between systems that leads to the need of defining myriads of ad hoc processes. The possibility to mislead an object, as it is already coded how many information per stage of lifecycle are needed, grows with the increase of generic terms for the same concept (e.g. space, process, resource, etc.). On the other hand, strict frameworks do not ease interoperability as they may not include systems or innovative objects. In designing a framework for built environment models, it should be also taken into consideration that every object, needs to be defined in according to the specific need that are identified in the process - Level of Information Need (LOIN) [17].

\section{References}

1. IEEE, Standard Computer Dictionary. A Compilation of IEEE Standard Computer Glossaries (1990)

2. Laakso, M., Kiviniemi, A.: The IFC standard - a review of history, development, and standardization. J. Inf. Technol. Constr. 17, 134-161 (2012)

3. Pauwels, P., Zhang, S., Lee, Y.C.: Semantic web technologies in AEC industry: A literature overview. Autom. Constr. 73, 145-165 (2017). https://doi.org/10.1016/j.autcon.2016.10.003

4. Building Smart, Linked Data Working Group (2018). http://www.buildingsmart-tech.org/ future/linked-data. Accessed 21 Jan 2019

5. Pauwels, P., Terkaj, W.: EXPRESS to OWL for construction industry: towards a recommendable and usable ifcOWL ontology. Autom. Constr. 63, 100-133 (2016). https://doi.org/10.1016/j.autcon.2015.12.003 
6. B. International, Open Standards - the basics (2014). https://www.buildingsmart.org/ standards/technical-vision/open-standards/

7. ISO, ISO 29481-1 - Building information models - information delivery manual - Part 1: Methodology and format (2016)

8. ISO, ISO 29481-2 - Building information models - information delivery manual - Part 2: Interaction framework (2012)

9. ISO, ISO 16739: Industry Foundation Classes (IFC) for data sharing in the construction and facility management industries (2013)

10. ISO, ISO 12006-3: Building construction - organization of information about construction works - Part 3: Framework for object-oriented information (2007)

11. Linked Building Data Community Group, Building Topology Ontology (BOT) (2019). https://github.com/w3c-lbd-cg/bot. Accessed 21 Jan 2019

12. Pauwels, P., Roxin, A.: SimpleBIM: from full ifcOWL graphs to simplified building graphs. In: 11th European Conference on Product Process Modelling, pp. 11-18 (2016)

13. Bonduel, M., Oraskari, J., Pauwels, P., Vergauwen, M., Klein, R.: The IFC to linked building data converter - current status. In: Proceedings of the 6th Linked Data Architecture Construction Workshop Semantic, pp. 34-43 (2018)

14. Rasmussen, M.H., Pauwels, P., Lefrançois, M., Schneider, G.F., Hviid, C.A., Karshøj, J.: Recent changes in the building topology ontology. In: 5th Linked Data Architecture and Construction Workshop (2017). https://doi.org/10.13140/rg.2.2.32365.28647

15. Schneider, G.F.: Towards aligning domain ontologies with the building topology ontology. In: 5th LDAC Work., Dijon, France, 13-15 November 2017

16. ISO, ISO 12006-2: Building construction - organization of information about construction works - Part 2: Framework for classification (2015)

17. ISO, UNI EN ISO 19650-1 - Organization of information about construction works Information management using building information modelling — Part 1: Concepts and Principles, 2018 